ción ha sido un instrumento considerado pertinente por muchos.

Finalmente, Borjón y Rosario (2019), señalan la importancia de la globalización, pues dentro del ámbito internacional, dicho proceso ha sido inevitable debido al comportamiento y desarrollo individual de las naciones, asimismo, ha jugado un rol fundamental debido a que cambió por completo el orden y comportamiento internacional, modificando incluso la estructura institucional y las relaciones económicas y políticas, viéndose influidas con la llegada de las nuevas tecnologías.

\section{EL NUEVO MODELO DE PARADIPLOMACIA EN MÉXICO}

Según Duchaceck (1990), el crecimiento de las actividades internacionales se ha dado mediante seis áreas, entre las que destacan la estabilización de oficinas encargadas de la representación de naciones ya sea en las capitales o en otras ciudades, las organizaciones de viajes sumamente publicitados de ejecutivos a diferentes naciones, el envío de misiones de funcionarios locales hacia el exterior, la organización de ferias internacionales para los productos locales tanto a niveles estatales como externos, la profundización de relaciones entre entidades federativas dentro de los ámbitos regionales, especialmente de las regiones fronterizas, y finalmente, la participación de burócratas locales en reuniones u organismos internacionales.

Ahora bien, la participación de México ante actividades internacionales ha sido numerosa, y se puede ver a través de diversos ejemplos, uno de los más claros es la parti- cipación que se tiene dentro de Conferencia de Gobernadores Fronterizos, la cual se establece con Estados Unidos, además cuenta con una gran cantidad de oficinas dedicadas a la atención a migrantes en el exterior, especialmente en Estados Unidos, asimismo, su participación dentro de foros internacionales ha sido notable.

Por su parte, Dávila, Schiavon y Velázquez (2008) mencionan otros ejemplos que son prueba de la participación internacional y de las actividades paradiplomáticas en las que México, a través de los años ha formado parte:

- En el año 2000, el gobernador del estado de México, de ese momento, Arturo Montiel, llevó a cabo diferentes estrategias que imponían un activismo político internacional, el cual inclusive superó las actividades comerciales y económicas de las administraciones previas. Efectuó una gira por América del Sur, en la que se reunió con importantes representantes públicos y privados, entre los que se encontraban los presidentes de Argentina y Chile de ese momento, Fernando de la Rúa, y Ricardo Lagos, respectivamente. Posteriormente, en el año 2003, el estado de México fue anfitrión del Foro de Biarritz, donde ocurrió el cuarto encuentro entre América Latina y Europa, tuvo lugar principalmente en Valle de Bravo, debido al planeamiento por parte del exgobernador, cabe destacar que este evento, ocurrió por primera vez fuera de Europa, lo cual permitió a Arturo Montiel obtener una gran visibilidad tanto a nivel nacional como internacional.

- En el año 2001, el exgobernador del estado de Chiapas, Pablo Salazar, creó la 
Coordinación de Relaciones Internacionales dentro de su estado, debido a que el Ejercito Zapatista de Liberación Nacional (EZLN) estaba teniendo una enorme visibilidad a nivel internacional, esta Coordinación tenía como objetivo el asesoramiento y apoyo cada una de las instancias del gobierno de Chiapas para llevar a cabo negociaciones, propuestas y proyectos con diferentes actores internacionales. Posteriormente, en el año 2002, el estado chiapaneco mantenía amistad con 43 naciones pertenecientes a los cinco continentes, así como también con una gran cantidad de organismos a nivel internacional. Finalmente, en el año 2004, Chiapas firmó junto con la Unión Europea, un convenio de Financiación con una duración de cuatro años, dicho convenio establecía un proyecto de cooperación con recursos por la cantidad de 15 millones de euros, con la finalidad de reforzar los trabajos gubernamentales para combatir la pobreza, así como también para la conservación de la Selva Lacandona.

- Durante la administración de Marcelo Ebrard como jefe de gobierno del entonces llamado Distrito Federal, se intensificó considerablemente la presencia internacional, ya que en menos de un año visitó países como Estados Unidos, China, Reino Unido y Alemania, asimismo, se reunió con una gran cantidad de mandatarios, entre los que se encuentran Lula da Silva de Brasil, Néstor Kirchner de Argentina, Michelle Bachelet de Chile, y el primer ministro de ese entonces de España, José Luis Rodríguez Zapatero, con los que negoció e institucionalizó mecanismos enfocados a la atracción de inversión ex- tranjera, promoción de las exportaciones locales, cooperación en áreas técnicas y sectoriales, y el acercamiento a comunidades de emigrantes en el exterior.

Finalmente, se deben destacar a las entidades federativas mexicanas que mantienen mayor actividad internacional, las cuales son: Nuevo León, el estado de México, Jalisco, Chiapas y Baja California. Una de las principales razones por las que se encuentran en esta lista, es que poseen una gran cantidad de oficinas enfocadas en asuntos internacionales que tienen una estructura burocrática. En el caso de Chiapas, como se mencionó con anterioridad, ha obtenido una presencia destacada dentro de la esfera internacional debido a la determinación de fundar la Coordinación de Asuntos Internacionales y al conflicto zapatista.

Por su parte, los estados de Nuevo León y Baja California igualmente son estados que cuentan con una fuerte relación con el exterior debido a la cuestión fronteriza con Estados Unidos, debido a esta situación, han tenido la oportunidad de contar con grandes flujos de inversión extranjera. Asimismo, como ya se mencionó anteriormente, la participación dentro de la Asociación de Gobernadores fronterizos ha fructificado las interlocuciones con Estados Unidos.

En el caso de Distrito Federal (ahora Ciudad de México), debido a las estrategias implementadas por parte de Marcelo Ebrard como jefe de gobierno, la entidad tuvo la oportunidad de incrementar en gran medida la presencia internacional, debido a que, en las gestiones previas, esto no era considera- 
do como una prioridad, dejando en segundo plano, las relaciones exteriores.

Sin embargo, se debe tomar en cuenta que las actividades enfocadas principalmente a las atracciones de inversión extranjera, la promoción del comercio internacional y el acercamiento a las distintas comunidades tanto nacionales como internacionales, son llevadas a cabo no solamente para la promoción del gobierno subnacional ante el Sistema Internacional, sino que significa un enorme y ventajoso posicionamiento para los líderes o mandatarios que las implementen, pues las actividades en escenarios exteriores significan un avance dentro de sus carreras personales.

\section{LAS ESTRATEGIAS DE MEDIACIÓN PARADIPLOMÁTICA}

Se plantea el cuestionamiento de cuál es el camino a seguir para la mediación de este tipo de conflictos con singularidades locales e internacionales, el mediador paradiplomático tiene que tener en cuenta que el papel de su mediación tiene dos sentidos en primera instancia una mediación local que permita al gobierno central establecer conversación con el gobierno local, en un segundo sentido, la mediación internacional permite al gobierno local establecerse en la agenda internacional y buscar relación con sus pares en el exterior.

Para que esto suceda se recomiendan dos ejes de acción de la mediación en conflictos derivados de la Paradiplomacia, en primera la discreción de las partes, de acuerdo con Fisher y Ury (1990), es mejor negociar fuera del foco mediático y la prensa militante mar- cando cada paso de la agenda pública, se necesita un estricto compromiso de secreto entre ambas partes.

El segundo eje es no imponer condiciones inquebrantables, ósea, que no se van a poder aceptar por el otro. Cada parte tiene derecho a tener posiciones mínimas bien establecidas y muy claras. Por lo que es importante al inicio y al final del proceso explicitarlas aludiendo a que no habrá ningún consenso en determinadas condiciones (Ortuño, 2017). La primera herramienta mencionada, la discreción del mediador en conflictos relacionados con la Paradiplomacia se requiere secrecía para llevar a cabo negociaciones entre las partes, por la manipulación que se ejerce sobre la agenda pública local y los intereses que se tienen con países extranjeros.

Por último, existen ciertas condiciones que no son negociables, en regiones que buscan su internacionalización en la periferia del estado central tienen características como el lenguaje o la cultura, así como su representación que resulta condiciones inquebrantables por una de las partes.

\section{MÉTODO}

El enfoque de la presente investigación es cualitativo, en donde se hace un diseño no experimental que se refiere a que se observan condiciones o situaciones ya existentes se basa en variables que no son manipuladas ni intervenidas por el investigador, en este tipo de investigación se observan los fenómenos tal cual se observan en su contexto natural para después analizarlos. 
Se procedió a la recopilación de un total de 30 fuentes para la construcción del marco teórico conceptual de "Los métodos de solución de conflictos en la Paradiplomacia: Los retos del mediador en la internacionalización de los gobiernos locales" donde fueron utilizadas como instrumento para generar conceptos, ideas y argumentos que fueron analizados desde una perspectiva crítica y analítica. Después se realizó el estudio de caso en el cual los datos pueden ser obtenidos desde una variedad de diferentes fuentes, tanto cualitativas como cuantitativas; pueden ser, documentos, registros de archivos, entrevistas directas, observación directa, observación de los participantes e instalaciones (Chetty, 1996).

Para la comprensión del problema de investigación se recopilaron fuentes secundarias para definir los conceptos de métodos alternos de solución de conflictos y la paradiplomacia, teniendo la información recopilada y analizada se realiza un estudio de caso, donde se observan diferentes ejemplos de paradiplomacia en Europa y América y se contrastan los resultados con lo sucedido en México. Para proceder a generar conclusiones, limitantes del estudio y recomendaciones.

\section{CONCLUSIONES}

A manera de conclusión, se puede destacar que la importancia de los gobiernos subnacionales ha incrementado con el paso del tiempo debido a la globalización, pues ha sido un proceso creciente que afecta a las naciones, y posiciona a las localidades con mayores ventajas, brindándoles la oportunidad de participar dentro de foros internacio- nales, lo que permite un mayor beneficio ya que en la actualidad tienen mayor coyuntura.

Sin embargo, este proceso puede llevar a conflictos derivados de shocks exógenos o endógenos que en un momento dado necesitan la intervención de mediadores para evitar controversias a grande escala. En este sentido la intervención de los MASC en el Sistema Internacional conlleva una importancia aun mayor, al poder involucrar herramientas de mediación tanto al interior de los estados como se pudo observar en el caso de Cataluña y al exterior en el posicionamiento de los gobiernos subnacionales.

En relación con eso, los métodos alternos de solución de conflictos y la mediación son herramientas que en un futuro aún más interdependiente el encuentro de diferentes puntos de vista e ideologías son necesarias para el bienestar común, la implementación de programas de internacionalización y por supuesto la participación de gobiernos locales en el Sistema Internacional.

Como mencionan diversos autores (Dávila, Schiavon y Velázquez, 2008; Zepeda, 2018) debido a la creciente interdependencia a nivel y al incremento de la descentralización y consolidación democrática en países como México, se espera que las actividades internacional y paradiplomáticas de los gobiernos subnacionales continúe creciendo. El proceso de la globalización ha cambiado las estrategias para todos los y esta situación de internacionalización permite que exista un nuevo espacio, en el que se encuentran nuevos modelos de funcionamiento y diversas posibilidades de gobernanza. 
Sin lugar a duda, los gobiernos locales tienen la oportunidad hoy más que nunca de incrementar su presencia y los alcances internacionales que tienen en sus manos, para poder cubrir intereses locales, debido a que, en una gran cantidad de ocasiones, se pueden ver ven obstaculizados por los gobiernos federales a los cuales pertenecen, por este motivo principalmente es que se busca ayuda al exterior, pues pretender encontrar un apoyo que muchas veces no tienen.

Por su parte, las mediaciones internacionales han surgido como un innovador proceso que abre paso a la una gran cantidad de estrategias, enfocadas principalmente en intensificar las relaciones amistosas, dejando a un lado los obstáculos que se puedan presentar, de esta manera, los conflictos se resuelven de una manera más precisa y democrática, buscando siempre cubrir los intereses de cada una de las partes involucradas.

Asimismo, es importante conocer las estrategias que se han ido adoptando por parte de los gobiernos subnacionales que han adoptado políticas relacionadas con las actividades paradiplomáticas, pues pueden servir como ejemplo a la hora de incorporar nuevas estrategias para los demás gobiernos locales, además, es imprescindible contar con el apoyo de la Federación a la que se pertenece, pues el éxito de sus gobiernos subnacionales son también importantes, debido a que se adquiere mayor apoyo por parte de la comunidad internacional.

\section{TRABAJOS CITADOS}

Aguirre, I. (2001) “¿Qué sentido tiene hablar de paradiplomacia? Una encuesta intertextual en torno a un neologismo polisémico" en Paradiplomacia: las relaciones internacionales de las regiones Aldecoa, Francisco; Keating, Michael.

Arenas, G. (2018). Paradiplomacia: de naciones y trayectorias. Papel político.

Buendía, A. (2012). Educación superior y aseguramiento de la calidad en México. CINDA. Butler, R. (1961). Paradiplomacy, in Sarkissian. Studies in diplomacy.

Berneo, F. E. (2019). Paradiplomacia y desarrollo territorial. Quito: Abya-Yala.

Borjón, J., y Rosario, J. (2019). Sociedad civil y conflictos internacionales: un modelo de mediación para la protección de los derechos humanos. Letras Jurídicas, (40), 15-35

Carrascal A. (2011) La mediación internacional en el sistema de Naciones Unidas y en la Unión Europea: evolución y retos de futuro, revista de mediación, 28-33 https:// revistademediacion.com/wp-content/uploads/2013/10/ Revista-Mediacion-8-03.pdf

Chetty S. (1996). The case study method for research in small- and médium - sized firms. International small business journal, vol. 5, octubre - diciembre.

Cornago, N. (2000). Diplomacia, paradiplomacia redefinición de la seguridad mundial. Madrid: Marcial Pons.

Carreón P. (2007). Paradiplomacia y su desarrollo en el mundo. Protocolo recuperado en http://www.protocolo. com.mx/internacional/paradiplomacia-y-su-desarrolloen-el-mundo/

Dávila, C., Schiavon, J., y Velázquez, R. (2008). La paradiplomacia de las entidades federativas en México. México: CIDE.

Dermawan, W., y Akim, A. (2020). Catalan Identity and P Catalan Identity and Paradiplomacy Str adiplomacy Strategy in Catalonia ategy in Catalonia's Independence Movement. Global: Jurnal Politik Internasional, 22(2), 317-337. DOI: http://dx.doi.org/10.7454/global.v22i2.485 
Deutsch, M. y Coleman P. T. (2000). The handbook of conf ict resolution. Theory and practice. San Francisco, Ca. Jossey-Bass Publishers.

Duchaceck, I. (1990) "Perforated Sovereignties: Towards a Typology of New Actors in International Relations" en Hans J. Michelmann y Panayotis Soldatos (eds.), Federalism and International Relations: The Role of Subnational Units, Oxford, Clarendon Press, 1-33.

Fisher, R. y Ury, W. Obtenga el sí. El arte de negociar sin ceder, Compañía Editorial Continental, México, 1990, pág. 62.

García A. (S.f) Mediación y Solución de Controversias en el Sistema Internacional. Centro de pensamiento Estratégico- Ministerio de Relaciones Exteriores.

Grau Vidiella, Marc. 2013. Inversión extranjera directa y la actividad internacional de las entidades subnacionales (B.A. Thesis in Political Science and International Relations). Mexico: CIDE.

Gastal, S. y Osmainsch, R. (2017). Ciudades globales, rankings y posibilidades para el turismo. Estudios y Perspectivas en Turismo.

Garcia-Waldman, Jiménez y Zapata-Morán, (2019), La paradiplomacia universitaria: La internacionalización de la educación superior en América Latina, Revista Política, Globalidad y Ciudadanía DOI: http://dx.doi. org/10.29105/pgc4.8-3.

Gómez, L. (2016). Negociación Internacional: Enfoque Estratégico. Universidad Externado de Colombia.

Gorjón, F., y Sáenz, K. (2009). Métodos alternos de solución de controversias. Enfoque eduactivo por competencias. México: Patria.

Harispe, A.y Araya, J. (2014). "Nuevos actores subnacionales en el sistema internacional: municipios y universidades". Ponencia presentada en el VII Congreso de Relaciones Internacionales del IRI, el I Congreso del CoFEl y el II Congreso de la FLAEI, Buenos Aires, Argentina, 26, 27 y 28 de noviembre de 2014.

Keating, M. (2002). «Naciones sin estado. Nacionalismo minoritario en la era global». En F. REQUEJO, Democracia y Pluralismo Nacional. Barcelona: Ariel Ciencia Politica.
Keohane R. y Nye J. (1977). Power and Interdependence: World Politics in Transition. Boston: Little Brown.

McMillan, Samuel Lucas. 2012. The Involvement of State Governments in US Foreign Relations. New York: Palgrave Macmillan.

Oddone, N. (2016). La paradiplomacia desde cinco perspectivas: Reflexiones teóricas para la construcción una realidad epistemica en América Latina. RELACIONES INTERNACIONALES, 47-81.

Ortuño, P. (2017). La mediación posible, El país, recuperado: https://elpais.com/ccaa/2017/10/07/ catalunya/1507397887_100551.html

Rivera, P., y Tamez, G. (2019). La mediación como mecanismo alternativo de solución de conflictos en las relaciones internacionales. México: Rechtikal.

Soja, E. w. (2005). Algunas consideraciones sobre el concepto de ciudades. Ekonomiaz, 48.

Soldatos, P. (1990). An Explanatory Framework for the Study of Federated States as Foreign-policy Actors. Clarendom Press.

Velázquez, R. (2007). La Paradiplomacia mexicana: Las relaciones exteriores de las entidades mexicanas. México: CIDE.

Zepeda, R. (2018). La paradiplomacia de las provincias canadienses: los casos de Quebec, Alberta y Columbia Británica. Revista de Relaciones Internacionales de la UNAM, (130), 53-77.

\section{María Gabriela Zapata}

Doctora en Relaciones Internacionales, Negocios y Diplomacia, Facultad de Ciencias Políticas y Relaciones Internacionales, profesora e investigadora de la UANL, miembro de la Red de Expertos en Paradiplomacia e Internacionalización Territorial, email: gabrielazapmor15@gmail.com 


\title{
La certeza jurídica de los acuerdos de mediación empresarial
}

\author{
The legal certainty of business mediation agreements
}

\section{Recibido: 07-10-2021 | Aceptado: 21-00-2021}

José Arturo Cen Puc*

* https://orcid.org/0000-0002-6834-3048

Universidad Autónoma de Yucatán, México

\section{Resumen}

La mediación empresarial genera mejores prácticas de gobierno corporativo, las empresas que quieren una mayor competitividad, tienen con la mediación un método que le garantice certeza en sus acuerdos, provocando relaciones empresariales más duraderas, ya que genera cultura de paz, confianza, honestidad y demás valores intangibles que benefician las relaciones empresariales que se dan entre los socios, los órganos de administración empresarial, sus colaboradores, proveedores, clientes y con las instituciones públicas.

Palabras clave: Métodos Alternativos de Solución de Conflictos, Mediación, Mediación Empresarial, Certeza Jurídica, Competitividad. s.

\section{Abstract}

Business mediation generates better corporate governance practices; companies that want greater competitiveness have mediation, which guarantees certainty in their agreements, causing more lasting business relationships. It generates a culture of peace, trust, honesty, and other intangible values that benefit business relationships between partners, direction boards, collaborators, suppliers, clients, and public institutions.

Key Words: Alternative Conflict Resolution Methods, Mediation, Business Mediation, Legal Certainty, Competitiveness.

\section{Cómo citar}

Cen Puc, J. A. La certeza jurídica de los acuerdos de mediación empresarial. MSC Métodos De Solución De Conflictos, 2(2). Recuperado a partir de https://revistamsc. uanl.mx/index.php/m/article/view/17 


\section{INTRODUCCIÓN}

La Los Mecanismos Alternos de Solución de Controversias pueden generar mayor competitividad para las empresas que fomenten dentro su organización la resolución de conflictos por vías más amigables, donde puedan ser las empresas en términos de sus intereses quienes busquen una solución consensuada, sin necesidad de someterlo a la decisión jurisdiccional.

Las empresas en México tienen una estimación de duración de dos años, esto puede ser debido a los diversos conflictos que se presente en su operación y relaciones comerciales.

En el presente trabajo se analizará como los Mecanismos Alternativos de Solución de Controversias fomentan mejores prácticas de gobierno corporativo, estableciendo que mecanismos se reconocen en el estado de Yucatán, definiendo a la conciliación, el arbitraje y la mediación.

Es la voluntad y la autonomía contractual, lo que le da validez a establecer un clausulado escalonado para el uso de la mediación, conciliación y arbitraje como métodos para solucionar los conflictos, sin necesidad de someterse a un proceso judicial, lo que provoca mayor efectividad, control en la solución de conflictos de manera económica y en menor tiempo.

Estableciendo a partir de las relaciones empresariales, la necesidad de una mediación empresarial para los conflictos de índole comercial y mercantil que involucren a la em- presa, enunciando el ámbito de aplicación de la mediación en el Estado, tomando en cuenta a la mediación llevada a cabo en centros privados o por mediadores privados. Se analizará los elementos de validez que garanticen la certeza jurídica de los acuerdos de mediación y como en el ámbito privado de la mediación es necesario ir más allá de lo establecido en la ley aplicable, para blindar dichos acuerdos.

\section{MECANISMOS ALTERNATIVOS DE SOLUCIÓN DE CONTROVERSIAS COMO MEJORES PRÁCTICAS DE GO- BIERNO CORPORATIVO}

La empresa genera un desarrollo económico y social, busca cumplir sus intereses y con ello formar una estructura que le ayude a lograr sus fines, esta dimensión de como una idea se vuelve de un modelo de negocio a una organización que se va construyendo y fortaleciendo día a día, es el resultado de la interacción continua de las personas que la integran.

La definición propia de empresa en México va asociada a una sociedad o persona moral, que en términos de la Ley General de Sociedades Mercantiles que en su artículo 1, señala que las diversas sociedades mercantiles podrán realizar toda clase de actos de comercio para cumplir con su objeto social. La legislación mexicana reconoce sociedades desde un solo socio la denominada Sociedad de Acciones Simplificada, sin embargo, son las sociedades que requieren mayor número de socios como la Sociedad Anónima, la Sociedad Anónima Promotora de Inversión y la Sociedad de Responsabilidad 
Limitada las que tienen mayor relevancia y existencia.

Todas las sociedades deben de estar legalmente constituidas, dotándose de derechos y obligaciones, entre socios, socios con colaboradores o empleados, socios con proveedores, socios con acreedores, socios con deudores, y demás relaciones que se van gestando desde el inicio de una idea que busca convertirse en un negocio.

La actividad empresarial se compone de diversos factores que le generan el capital, el trabajo que va encamino a la producción, extracción, transformación, circulación, distribución, intercambio, tráfico, etc., de satisfactores destinados al público en general, a un mercado determinado, realizadas de manera estable y profesional, en nombre y por cuenta de un empresario con la finalidad de especulación y bajo riesgo (León \& González, 2018, pág. 2).

Se estima que en México el $90 \%$ de las empresas son consideradas Empresas Familiares, sin embargo es necesario por lo menos aproximarse a una definición de empresa familiar, ya que hoy en día hay diferentes definiciones que tomas diversas características para su establecimiento, mismas que fueron estudiadas en los años 70 y que obtuvieron más auge en los 80, principalmente en Estados Unidos, desde esas primeras definiciones puede inferirse que es una empresa controlada por una familia, que exista alguna influencia estratégica de los miembros de la familia en la administración, las propiedades estén en manos de miembros de la familia y que busquen trascender por generaciones.
En un estudio realizado sobre las empresas familiares, segmentaron las empresas que son familiares de las que no lo son, identificando si existe un familiar que posea al menos el $50 \%$ de la propiedad y si tiene al menos un miembro de esta misma familia ocupando un puesto directivo. Las respuestas afirmativas a estas preguntas muestran que el $83 \%$ de las empresas en México puede considerarse como familiares. (San Martín Reyna \& Durán Encalada, 2017)

Ahora bien, estas relaciones y actividades deben de ser reguladas o estipuladas mediante acuerdos o instrumentos que den certeza de la empresa y por ende de los actos de comercio que realice para cumplir con sus fines, esta regulación busca prevenir conflictos y garantizar el buen funcionamiento de esta.

A nivel empresarial las relaciones que se van gestando desde el inicio de una empresa, involucra diferentes personas, procesos y etapas, partiendo desde la integración societaria: los socios, que al celebrar su acta constitutiva generan un consentimiento de participar y cumplir los fines e intereses personales y colectivos, seguidamente la integración de sus órganos de administración, derivando en las relaciones laborales que pudieran tener con colaboradores, para poder ofertar sus bienes o servicios, interactuando con prospectos y clientes, a los cuales para garantizar dichos bienes y servicios, se requieren en ocasiones que la empresa cuente con proveedores, inversionistas, también involucra relaciones con instituciones públicas para garantizar la legalidad de las actividades, así como relaciones con otras 
empresas, todo eso establece una gama de posibilidades que pueden dar pie a diversos conflictos, el conflicto se puede afirmar que es una percepción, es decir, deriva de la interpretación de las partes con relación a los hechos que le dan origen (Medina, 2018, pág. 70).

Consideramos que el conflicto es prevenible con una buena estructura, con transparencia y claridad en las comunicaciones y con la implementación de mejores prácticas corporativas.

Para una mayor competitividad dentro la práctica empresarial que establezca la permanencia en el tiempo y logre una mayor trascendencia, es necesario que estas relaciones, actividades y toma de decisiones se den en un ámbito de honestidad, transparencia, responsabilidad, eficiencia y legalidad, para ello es necesario el establecimiento de un gobierno corporativo.

El Gobierno Corporativo comprende el conjunto de normas, principios, elementos estratégicos, operacionales y administrativos, que buscan maximizar el valor de las sociedades mediante la regulación del diseño, integración y funcionamiento de los órganos que las gobiernan y controlan, dando mayor transparencia conforme a los intereses de los accionistas y el público (León \& González, 2018, pág. 358).

Para la ejecución y realidad del gobierno corporativo es necesario que se establezca una estructura organizacional de la empresa eficaz, tales como el consejo de administración, comités, consejo familiar, directores generales, auditores, consejeros independientes, etc.

El Consejo Coordinador Empresarial ha sido un impulsor para el establecimiento de mejores prácticas corporativas, desde el 2006 ha publicado el Código de Principios y Mejores Prácticas de Gobierno Corporativo, siendo su adhesión voluntaria y busca que las empresas incorporen y adopten sus principios en su estructura organizacional y de gobierno corporativo para lograr una mayor competitividad entre sí y con el mercado en el que se encuentre inmerso.

En dicho código se señala la importancia de que en las relaciones entre los socios, en el adecuado desempeño de las funciones y obligaciones que tiene que atender el consejo de administración y sus órganos de gobierno, al existir diferencias se eviten dañar la imagen de la sociedad y dificultar la operación en perjuicio de colaboradores, proveedores o algún tercero interesado, para cual sugiere que la sociedad tenga definido una procedimiento para la prevención y solución pacífica y negociada de los conflictos entre los accionistas y/o entre los consejeros, privilegiando los mecanismo alternativos de solución de controversias (Consejo Coordinador Empresarial, 2018, pág. 18).

A partir de la reforma constitucional de 2008, donde se estableció en su artículo 17 y 18 a los Mecanismos Alternativos de Solución de Controversias (MASC) son una realidad que abona a una cultura de la paz y el bienestar social, es un hecho que la impartición de justicia pronta y expedita cada día es más compleja, los tiempos que se llevan 
en resolver los conflictos, genera un nivel de desconfianza en las instituciones que tienen este deber.

Así es como los MASC se vuelven en la alternativa eficaz para resolver conflictos entre particulares en menor tiempo, con mayor consenso entre las partes, el reto es ampliar su aplicación en cualquier situación que genere conflicto y se llegue a un acuerdo, se garantice una reparación del daño y una justicia retributiva.

Los mecanismos se desenvuelven con un contexto que involucra más allá de la ciencia del derecho, ya que es multidisciplinar, involucrando incluso modelos de negociación y mediación, haciendo necesario el desarrollo de políticas públicas, reformas estructurales, leyes especializadas estatales y federales, reglamentos y tratados internacionales, así como facilitadores especializados que requieren una capacitación constante, que en algunos casos no necesariamente tienen que ser abogados y que llevan a cabo los procesos de los mecanismos alternativos en centro de mediación públicas o privadas.

\section{LOS MECANISMOS ALTERNATIVOS DE SOLUCIÓN DE CONTROVERSIAS EN EL ESTADO DE YUCATÁN.}

Como ya se señaló el establecer a nivel constitucional los Mecanismos como una alternativa, ha servido para que se vayan integrando en nuestro sistema jurídico mexicano, para el 2019 se contaba con 26 leyes estatales de Mecanismos Alternativos, con diferentes denominaciones, "conceptos y contradicciones" (Gorjón \& Steele, 2020, pág. 25).
Lo anterior, resalta la importancia de tener claridad en los conceptos y ámbitos de aplicación, en este trabajo nos centraremos en el análisis de la Ley de Mecanismos Alternativos e Solución de Controversias en el Estado de Yucatán, publicada en el 2009, para determinar elementos de validez que den certeza jurídica en los acuerdos de mediación empresarial.

En el Estado de Yucatán se reconocen como Mecanismos Alternativos:

...todo procedimiento de solución de controversias de índole civil, familiar, mercantil y penal incluyendo los casos de adolescentes en conflicto con la ley, tales como la mediación, conciliación y los demás que permitan a las personas prevenir conflictos previstos en otras disposiciones legales o, en su caso, solucionarlos sin necesidad de intervención de los órganos jurisdiccionales, salvo aquellos que tiendan a garantizar la eficacia del convenio adoptado por los participantes y el cumplimiento del mismo (Ley de Mecanismos Alternativo de Solución de Controversias del Estado de Yucatán, 2009, art. 4 fracción X).

Expresamente se señalan a la mediación y a la conciliación, se deja la posibilidad de las demás que contemplen en otras disposiciones legales que permitan prevenir conflicto, sin necesidad de intervención de los órganos jurisdiccionales, tal como se establece en el Juicio Arbitral, que contempla el Código de Procedimientos Civiles del Estado de Yucatán. 
Ante estos métodos alternativos aplicables, es necesario establecer los parámetros para su desarrollo, es decir sus principios tales como la voluntariedad, la buena fe, neutralidad, Imparcialidad, equidad, legalidad, honestidad, flexibilidad, oralidad, consentimiento informado, intervención mínima y economía, estos contemplados en Ley Estatal.

La voluntariedad como principio que se basa en la libre autonomía de las partes a celebrar acuerdos y compromisos, pero antes de ello la libertad de acceder a participar en estos métodos, incluso antes de cualquier instancia jurisdiccional, teniendo la voluntad y libertad de decidir sobre la información que revelan, así como de llegar o no a un convenio o acuerdo.

La legalidad, que es el límite a la voluntad de las partes, la ley, la moral y las costumbre, que los conflictos sean susceptibles de ser mediables y que no vayan contra el orden público.

La confidencialidad de la información que se vierta en los procesos sometidos en los métodos alternativos.

La Equidad, resolver de manera adecuada, con proporcionalidad y razón, sin que se otorgue ventaja a alguna de las partes.

Por mencionar algunos principios que buscan garantizar una participación de las partes para proponer una solución en el conflicto, lo cual tiene diferencia de un proceso jurisdiccional, donde se espera la resolución de un juez, en los métodos se busca un con- senso, aunado a que son un sistema integrado, son reconocidos internacionalmente, flexibles, abona a la creatividad, son más agiles y rápidos, así como económicos.

\section{LA CONCILIACIÓN.}

Es el mecanismo voluntario mediante las partes involucradas en conflicto, encuentran la manera de resolverlo con la intervención de un facilitador, se desarrolla mediante la promoción del dialogo hasta llegar a una solución satisfactoria, el tercero facilitador propone una solución a partir del debate, persuadiendo a las partes.

La conciliación se puede apegar a lineamientos establecidos por instituciones arbitrales, el facilitador deberá ser experto en la materia de la controversia, el procedimiento puede terminarse en el momento que las partes lo decidan, al terminarse el procedimiento se formula un informe de los acuerdos tomados, este acuerdo es vinculante, es considerado una etapa previa en el arbitraje y en algunos modelos de mediación.

\section{EL ARBITRAJE}

El arbitraje es el mecanismo utilizado con frecuencia en la resolución de controversias en el comercio internacional.

Es un procedimiento heterocompositivo extraprocesal, fundado en el principio de la autonomía de la voluntad de las partes, que enaltece el principio pacta sun servanda, esto es, que las partes someten sus diferencias a la consideración de un particular, un 
árbitro, quien actuará según sus potestas, bajo la tutela del principio erga omnes basado en el ius mercatorum o lex mercatoria y en la lex fori (Gorjón \& Steele, 2020).

Es un proceso especializado vinculante, en donde los arbitros dan la solución, por lo que deben ser expertos en la materia que estan resolviendo, las partes designan el idioma, el proceso y el derecho aplicable al conflicto, pueden establecer si deciden someterse a la resolución de una institución arbitral permanente, para lo cual el procedimiento se desarrollará conforme al reglamento de la institución designada; o bien puede establecerse que las partes se someterán a una resolución de un procedimiento arbitral Ad hoc, para lo cual deberán nombrar a los árbitros o establecer los modos o formulas, asi como determinar el lugar de la sede o emplazamiento del tribunal arbitral y fijar las normas de procedimiento.

Las sentencias o laudos arbitrales no son impugnables, por lo que tienen fuerza de sentencia judicial ejecutoriada, esta exigencia se puede hacer de la misma forma que las sentencias dictadas en los tribunales ordinarios nacionales o extranjeros, y bastara con acudir a instancia de parte a un órgano jurisdiccional acordado para solicitar la ejecución del laudo.

\section{LA MEDIACIÓN}

Es un método de solución de conflictos donde las partes son guiadas por un tercero, quien los asiste con la finalidad de facilitar las vías del diálogo y la búsqueda de un acuerdo. Este proceso es vinculante, satisface los inte- reses particulares y públicos, es un método rápido y económico, el procedimiento puede terminar en el momento que dispongan las partes, el convenio o acuerdo es voluntario, tiene que ser ratificado ante los centros públicos de mediación, en Yucatán la mediación privada puede ser ratificada ante notario, si el conflicto no ha sido expuesto en algún ámbito jurisdiccional, para que sea ejecutivo dicho acuerdo deberá acudirse a un órgano jurisdiccional, en caso de incumplimiento del acuerdo, el conflicto puede llevarse mediante proceso jurisdiccional.

La mediación gestiona el conflicto, es el método más cercano a nuestras relaciones diarias que abona a una cultura de la paz y bienestar.

Es disruptivo porque implica un mejoramiento de nuestro sistema y por lo tanto, un cambio de paradigma en la impartili ción de justicia privilegiando la movilización del proceso, por el de la gestión y transformación del conflicto como procedimiento, generando la ciudadanización de la justicia (Gorjón, 2017, pág. 24).

En ese sentido, ante el desarrollo de los MASC se puede considerar cada vez más que la mediación es una ciencia cuyo objeto de estudio radica en el estudio de los conflictos sociales, que permitan una cohesión social, impulsa la concertación y un crecimiento ordenado, que al igual que otras ciencias tiene un fin claro y determinado, rasgo distintivo de toda ciencia, en caso de la mediación su fin último es la paz (Gorjón, Mediación, ciencia social emergente, 2016, pág. 11). 


\section{LA MEDIACIÓN EMPRESARIAL}

La resolución de conflictos que involucren relaciones empresariales, entendidas estas las que se crean entre sus socios, órganos de administración, estructura organizacional, colaboradores, empleados, proveedores, prospectos, clientes, instituciones públicas, que involucren o se deriven de esta relación mercantil, que no necesariamente sean comerciales, podemos determinarla como Mediación Empresarial.

Bajo la premisa de que todo lo que se puede arbitrar comercialmente es mediable, sobre todo en el comercio internacional, es común pensar en el arbitraje como el principal método de solución de conflictos, sin embargo, este trabajo pretende establecer que la mediación puede ser una vía previa al arbitraje, evitando así resolver el conflicto incluso jurisdiccionalmente.

A nivel empresarial siempre será preferible la optimización del tiempo y recurso, así como el del cuidado de una imagen corporativa ante los conflictos que se susciten, es por lo que se afirma que la mediación empresarial presenta estas ventajas, además de la flexibilidad, simplicidad y que permite tener opciones de procedimientos para dar solución a los conflictos, presentado opciones validas y efectivas, que busquen democratizar el ámbito de solución de controversias mercantiles o comerciales.

El consentimiento al sometimiento a una mediación empresarial se basa a la voluntad de las partes en su autonomía contractual, desde la constitución de la sociedad, en los estatutos sociales se puede señalar estos mecanismos para la solución de conflictos, siendo los Estatutos Sociales las reglas, características, condiciones y fines que rigen las relaciones societarias, dando pie al nacimiento de la empresa y que generará estas relaciones.

Ante ello, será necesario que los socios realicen acuerdos referentes a la solución de conflictos a través de los métodos alternativos de solución de conflictos, que se establezcan en un apartado especial de los Estatutos, un clausulado med-arb para garantizar el uso escalonado de la mediación y el arbitraje.

Si la empresa desde su concepción lo establece, esta práctica se permea en toda su estructura, en el capital humano con el que cuenta y en relaciones siendo más competitiva, generando un ambiente empresarial con un enfoque de la cultura de paz, confianza, honestidad, empoderamiento, felicidad, fidelización, innovación, modernidad, prestigio, productividad, rapidez, reputación corporativa, transparencia, como valores intangibles dentro y fuera de la empresa.

Los intangibles son un valor sustentado en el capital intelectual, generado competitividad, beneficios, valor y adaptabilidad.

Por nombrar algunos conflictos que pueden ser sometidos a esta mediación empresarial serian:

- Falta de acuerdo para la diversificación de capitales.

- Buscar acuerdo para la contratación de proveedores o acreedores. 
- Arreglos de relaciones contractuales con clientes.

- Desacuerdos entre socios.

- Desacuerdos en el desarrollo de la estructura organizacional.

- Acuerdos sucesorios, principalmente en empresas familiares.

- La admisión de capital familiar

- Exclusión de socios.

- Conflictos con deudores de la empresa.

- Conflictos con colaboradores y empleados.

Es necesario hacer mención que la mediación empresarial tal como se propone hasta ahora contempla la mediación mercantil y comercial en los términos de los conflictos que puede derivarse de lo establecido en artículo 75 del Código de Comercio. (Código de Comercio, 2018)

\section{APLICACIÓN DE LA MEDIACIÓN EMPRESARIAL EN YUCATÁN}

En la legislación de Yucatán se establece a la mediación como el procedimiento voluntario en el cual un facilitador imparcial y sin facultad para sustituir las decisiones de las personas involucradas en una controversia, las asiste con la finalidad de facilitar las vías de diálogo y la búsqueda en común de un acuerdo que contenga la voluntad de las partes, sin necesidad de recurrir al procedimiento judicial (Ley de Mecanismos Alternativo de Solución de Controversias del Estado de Yucatán, 2009, Art. 3 Fracc. XI).

Este mecanismo será aplicado por el Centro Estatal de Solución de Controversias, me- diante los facilitadores institucionales del propio centro estatal o facilitadores privados de solución de controversias, adscritos que se encuentren certificados ante el Centro Estatal, los cuales puedes realizarlo sin necesidar de pertenecer a un Centro Privado de Solución de Controversias.

Son suceptibles de mediación los conflictos - las diferencias que se susciten entre las personas interesadas con relacion a algún hecho, derecho, contrato, obligación, acción o prestación, siempre que los asuntos puedan ser objeto de transacción en este caso comercial o mercantil, siempre que no afecte a la moral, derechos de terceros, al orden público o derechos irrenunciables.

La mediación empresarial puede ser aplicado en cualqueir momento, incluso si ya existe un proceso judicial respecto al conflicto y en materia mercantil siempre que no se contravengan las diposiciones legales aplicables. Una persona moral puede ser parte de un proceso de mediación, por conducto de sus representantes o apoderados legales.

Si no existiera algun proceso judicial puede realizarse ante un Centro Privado o Facilitador Privado, quienes deberan refrendar su certificación y registro cada tres años, cumpliendo con las obligaciones que señala la Ley de Mecanismo Alternativos de Solución de Controversias del Estado de Yucatán y el reglamento aplicable.

En cuanto a los centros privados de mediación, estos deben de estar constituidos como una sociedad civil, contar con facilitadores debidamente certificados, de igual forma 
deben contar con el reglamento institucional para su desempeño, tener las instalaciones adecuadas para las sesiones, entre otros.

El proceso de mediación se desarrolla en sesiones orales con la participación de las partes que solicitan la intervención para la solución del conflicto, esta sesiones pueden ser conjuntas o individuales, sin la participación de teceros, velando por el cumplimiento de los principios rectores de los mecanismos alternos, de la sesión llevada a cabo no se levantará constancia alguna, siempre en cumplimiento del principio de confidencialidad del proceso y del conflicto, con excepcion del convenio que resulte como solución del conflicto, sin embargo, las declaraciones emanadas en dichas sesiones no podrán ser presentadas como prueba en algún proceso judicial.

A la solicitud realizada por las partes, se continuará con la invitacion a la parte contraria para realizar una entrevista incial, donde se señale el mecanismo y sus principios rectores, si acepta dicha invitación se dará inicio al procedimiento de mediación, mediante la sesión respectiva, donde se buscará llegar a un acuerdo de solución, siendo que si una sesión no es suficiente puede citarse a otra. La mediación concluye con el convenio que se redacte, en él se establecerán los acuerdos a los que se llegaron y que dan la solución total al conflicto, otra forma de concluirse es mediante la decisión del facilitador al verificar que no hay un acuerdo satisfacotrio, por solicitud de alguno de los mediados o por ambos derivado de la negativa de suscribir el convenio.

\section{CERTEZA JURÍDICA DE LOS ACUERDOS DE MEDIACIÓN CELEBRADOS EN LOS CENTROS PÚBLICOS}

Los Mecanismos alternativos de Solución de Controversias tienen su fundamento en el principio de autonomía de la voluntad de las partes reconocido internacionalmente, es un derecho universal presente en la mayoría de las sociedades y un sustento legal reconocido a nivel mundial que les otorga una seguridad jurídica a sus resultados (acuerdos, convenios, laudos) los hace vinculantes a las partes, en un esquema multidisciplinario, interdisciplinario y mul-tidimensional (Gorjón, 2017, pág. 67).

Para la validez y certeza del convenio o acuerdo de mediación el artículo 53 de la Ley de Mecanismos Alternativo de Solución de Controversias del Estado de Yucatán, señala:

I. Deberá constar por escrito;

II. Señalar hora, lugar y fecha de su celebración;

III. Contener el nombre o denominación y los datos de identificación de los mediados o conciliados, así como la referencia y copia del documento oficial con el que se identifiquen. Cuando en el procedimiento hayan intervenido personas morales, deberá hacerse constar el documento con el que sus representantes acreditaron dicho carácter, el cual deberá contar con poder bastante para transigir, enajenar y obligar a su representada, y anexar copia certificada del mismo;

IV. Describir el conflicto y demás antecedentes que resulten pertinentes; 
V. Las cláusulas contendrán la descripción precisa, ordenada y clara de los acuerdos alcanzados por las partes, y las obligaciones de dar, hacer o tolerar, así como las condiciones, términos, fecha y lugar de cumplimiento, incluyendo cualquier compromiso moral a cargo de cualquiera de los interesados que no esté prohibido por la ley; VI. Contar con la firma de quienes lo suscriben y en caso de que no sepa o no pueda firmar alguno de los mediados o conciliados o ambos, estamparán sus huellas dactilares, firmando otra persona en su nombre y a su ruego, dejando constancia de ello, así como llevar el nombre y la firma del facilitador;

VII. Previa certificación del titular del Centro, se entregará un ejemplar del convenio a cada una de las partes y se comunicará mediante oficio a la autoridad que canalizó en su caso la atención de la controversia, así mismo deberá conservarse un ejemplar en los archivos del Centro según corresponda.

En los convenios celebrados en Centros Públicos, las partes y el facilitador institucional, deberán comparecer inmediatamente ante el Director General del Centro, el Subdirector de la oficina regional o a la autoridad competente de la Fiscalía General de Justicia del Estado, con la finalidad de ratificar su contenido, se reconozcan las firmas y lo certifique, levantando constancia, teniendo un carácter ejecutivo, siempre que no se haya planteado controversia judicial, si hubiese sido remitido por un Juez, se le hará de su conocimiento para que sea reconocido y se le otorgue el carácter de sentencia con efectos de cosa juzgada, sin que se necesite su ratificación.

\section{CERTEZA JURÍDICA DE LOS ACUERDOS DE MEDIACIÓN CELEBRADOS EN LOS CENTROS PRIVADOS DE MEDIACIÓN O MEDIADOR PRIVADO}

La Ley de Mecanismos Alternativos de Solución de Controversias en el Estado de Yucatán, señala que, para los convenios celebrados en centros privados, si el conflicto mediado haya tenido lugar en el desarrollo de un proceso jurisdiccional, deberá ser ratificado ante autoridad judicial que conozca sobre dichos procedimientos, para que sea reconocido y se le otorgue el carácter de sentencia con efectos de cosa juzgada.

Si el convenio parte de un conflicto que se haya tramitado antes del inicio de cualquier proceso jurisdiccional, satisfaciéndose los requisitos establecidos en la ley, este podrá ser ratificado ante el titular del Centro Estatal u oficia regional, la autoridad competente de la Fiscalía del Estado o el Notario Público que las partes designen, siendo que una vez certificado el convenio tendrá carácter ejecutivo.

Tiene relevancia la ratificación del convenio de mediación privada celebrada ante notario, ya que no en todos los Estados del País se regula la mediación privada y fomenta una mayor aplicación, sin embargo, hay que tener atención en dicho convenio y ratificación para que no carezca de validez. 
En ese orden de ideas, se debe establecer que el efecto de la ratificación hecha ante Director del Centro Estatal, Subdirector de los Centros Regionales, del Centro Público de Solución de Controversias o notario público, en términos de la misma ley es que el acto de acudir ante él es el de manifestar que su voluntad la suscripción del documento, reconociendo sus firmas.

Por su parte la Ley del Notariado del Estado de Yucatán, en su artículo 110 faculta al Notario público a realizar actos fuera de su protocolo y en su fracción VIII señala el de ratificar el convenio de mecanismos alternativos de solución de controversias entre dos o más personas, sin embargo en el mismo artículo limita la autentificación o ratificación de firmas las cuales no tendrá más efectos que acreditar que las mismas fueron puestas por las personas a quienes se les atribuyen, sin calificar sobre la validez y licitud de los documentos que contenga.

Lo anterior hace pertinente que para que la mediación privada tenga mayor fuerza, genere confianza y garantice su validez, se tiene que utilizar otros elementos que garanticen los acuerdos como válidos y ejecutables, para ello un buen ejercicio sería otorgarle al acuerdo de mediación un rango similar al que se le otorga a un laudo arbitral comercial, es decir que se considere una sentencia y que traiga aparejada ejecución, se le considere un título ejecutivo, dotada de la presunción de legalidad juris tamtum y se genere una reversión de la carga de la prueba, todos estos rubros son considerados como Elementos de control a prori (Gorjón, 2020, pág. 16).
Los elementos de control a priori se sustentan en principios internacionales establecidos en la convención sobre el Reconocimiento y Ejecución de Sentencias Arbitrales Extrajeras en su artículo 5, así como en el artículo 19 de la Ley Modelo de la CNUDMI sobre Mediación Comercial Internacional y Acuerdos de Transacción Internacionales Resultantes de la Mediación de 2018, en la legislación nacional en el artículo 1457, 1461,1462 y 1463 del Código de Comercio. (Código de Comercio, 2018)

Que, si bien no están contempladas en la ley específicamente para mediación, el objetivo es blindar el acuerdo de mediación, ya que es una obligación del mediador dictar acuerdos válidos y ejecutables.

Dichos Elementos de control a priori, Gorjón (2020) señala que, para el Acuerdo de Mediación y conciliación, son:

- Inexistencia o nulidad del compromiso (Capacidad de las Partes)

- Estado de indefensión de alguna de las partes (trato igualitario)

- Incongruencia del contenido del acuerdo (extra petitia)

- Irregularidades en el procedimiento de mediación

- Falta de obligatoriedad del acuerdo de mediación (nulidad)

- Contrario al Orden Público

- Materia no mediable

Así el acuerdo de mediación privada además de los establecidos en la Ley de mecanismos para el Estado de Yucatán, se debe garantizar que la primera notificación a cada una de las partes sea de manera per- 
sonal, durante el procedimiento se debe observar un trato igualitario a cada una de las partes, propiciando la equidad en las intervenciones que tengan las partes, el acuerdo no debe entrar a otros esquemas que no le correspondan, no debe ser contrario al orden público y ser un conflicto mediable, que no exponga derechos de tercero o irrenunciables.

\section{CONCLUSIONES}

La mediación en el ámbito empresarial como un método para solucionar los conflictos genera valor y competitividad a la empresa, los que hará un diferenciador en el mercado en el que se encuentren inmersos, diferenciadores que hoy en día se sustenta cada vez en los valores intangibles con las que cuenta, tener a la mediación garantiza mejores prácticas de gobierno corporativo.

El éxito para que la mediación empresarial tenga mayor aplicación en el Estado de Yucatán, radica en la certeza jurídica y el blindaje, en los acuerdos de mediación celebrados por las partes, si bien su incumplimiento puede dar lugar a otro mecanismo o bien iniciar algún proceso jurisdiccional, se pueden determinar un clausulado de contratación y de regulación de las relaciones que emanen con los diversas agentes con los que se interactúa, donde se vincule los métodos alternos para solucionar los conflictos que se vayan suscitando, teniendo a la voluntad de las partes y la autonomía contractual como principios rectores de los acuerdos, por ende fomentar la cláusula med-arb, que establezca de manera escalonada a la mediación, la conciliación y el arbitraje, dejando a un lado las vías jurisdiccionales, provocará en buena medida la descentralización de la justicia a las instituciones jurisdiccionales.

El reto sin duda será en la mediación privada, Yucatán es de los pocos estados que la contempla, sin embargo, en cuanto a su vinculación con los Notarios para la ratificación de los acuerdos, no la dota de la certeza necesaria, por ende es imperativo que el mediador privado aplique el mayor blindaje para garantizar su validez, o bien preferir acudir a los centros públicos de mecanismos alternativos de solución de controversias, para su ratificación, ante lo cual consideramos que podría ampliarse a nivel notarial una ratificación de la voluntad, más allá del reconocimiento de las firmas.

Ante ello, el adoptar los elementos de control a priori establecidos en el laudo arbitral comercial al acuerdo de mediación, impulsa su certeza y validez.

Prácticamente todo los conflictos comerciales y mercantiles son mediables, las empresas pueden llevar cualquier conflicto a la mediación, lo que se traduce en un ahorro económico y de tiempo ya que los conflictos se resuelven en menor tiempo que en un proceso judicial, lo que para sus actividades comerciales se refleja la optimización de sus recursos estructurales, de capital humano y de sus relaciones, fomentando ante los problemas el dialogo, la negociación, una cultura de la paz y el bienestar, lo que se transforma en una sociedad más responsable e innovadora. 


\section{TRABAJOS CITADOS}

Camara de Diputados del H. Congreso de la Unión. (28 de febrero de 2018). Código de Comercio. México : Diario Oficial de la Federación .

Consejo Coordinador Empresarial. (2018). Código de Principios y Mejoras Prácticas de Gobierno Corporativo. México : Consejo Coordinador Empresarial.

Gorjón, F. (2016). Mediación, ciencia social emergente. Comunitania. Revista Internacional de Trabajo Social y Ciencias Sociales, 9-25.

Gorjón, F. (2017). Mediación su Valor Intangible y Efectos Operativos "Una visión integradora de los métodos alternos de solución de conflictos". Ciudad de México: Tirant lo Blanch.

Gorjón, F. (2020). La mediación como vía al bienestar y la felicidad. Ciudad de México: Tirant lo Blanch.

Gorjón, F., \& Steele, J. (2020). Métodos Alternativos de Solución de Conflictos. México: Oxford University Press.

León, S., \& González, H. (2018). Sociedades Mercantiles e Introducción al Derecho Mercantil. Ciudad de México: Oxford University Press.

Ley de Mecanismos Alternativo de Solución de Controversias del Estado de Yucatán. (24 de Julio de 2009). Diario Oficial del Gobierno del Estado de yucatán. Yucatán, México: H. Congreso del Estado de Yucatán.

Medina, L. (2018). Negocios Familiares en México; guia para empresarios, introducción para consultores. México: Colegio Nacional de Correduría Pública Mexicana; Miguel Ángel porrúa.

San Martín Reyna, J. M., \& Durán Encalada, J. A. (2017). Radriografía de la Empresa Familiar en México. San Ándres Cholula, Puebla, México: UDLAP.

\section{José Arturo Cen Puc}

Abogado egresado de la Universidad Autónoma de Yucatán, estudiande de la maestría en Derecho Procesal Civil y Familiar de la Universidad Autónoma de
Yucatán, asesor jurídico para empresas; fundador de Ars Comunidad S.C.P., empresa cultural enfocada al desarrollo de emprendimientos en la industria creativa jose.cen@correo.uady.mx 